FERNANDA AYANE DE OLIVEIRA SANTOS

\title{
AVALIAÇÃO DA DIFERENÇA DA RESPOSTA IMUNE EM CAMUNDONGOS NEONATOS UTILIZANDO ANTÍGENOS DE MEMBRANA EXTERNA DE Neisseria meningitidis B COMPLEXADOS COM DOIS DIFERENTES ADJUVANTES
}

Dissertação apresentada ao Programa de Pós-Graduação Interunidades em Biotecnologia USP/ Instituto Butantan/ IPT, para obtenção do Título de Mestre em Biotecnologia.

Orientadora: Prof. Dra. Elizabeth Natal De Gaspari

Versão corrigida. A versão original e eletrônica, encontra-se disponível tanto na biblioteca do ICB quanto na Biblioteca Digital de Teses e Dissertações da USP (BDTD) 


\section{RESUMO}

SANTOS, F. A. O. Avaliação da diferença da resposta imune em camundongos neonatos utilizando antígenos de membrana externa de Neisseria meningitidis B complexados com dois diferentes adjuvantes. 2017. 92 f. Dissertação (Mestrado em Biotecnologia) - Instituto de Ciências Biomédicas, Universidade de São Paulo, São Paulo, 2017.

Os adjuvantes são moléculas, compostos ou complexos macromoleculares que aumentam a potência e a longevidade da resposta imune específica aos antígenos. A sua adição na preparação vacinal aumenta, sustenta e dirige a imunogenicidade de antígenos, modulando de forma eficaz respostas imunes apropriadas, reduzindo a quantidade de antígeno ou número de imunizações necessárias e melhorando a eficácia de vacinas em recém-nascidos, idosos ou indivíduos imunocomprometidos. O objetivo desse estudo foi avaliar a imunogenicidade das preparações antigênicas baseadas em vesículas de membrana externa (OMVs) de Neisseria meningitidis $\mathrm{B}$ complexados com dois diferentes adjuvantes, o lípide catiônico brometo de dioctadecildimetilamônio (DODAB-BF) e hidróxido de alumínio (HA) ou $\left(\mathrm{Al}(\mathrm{OH})_{3}\right)$ utilizando a via intranasal e a via subcutânea em camundongos neonatos Swiss aplicando o sistema de imunização prime-booster. Como métodos de estudo foram utilizadas as técnicas universais imunológicas como: Immunoblot, DOT-ELISA, ELISA e ELISpot visando à avaliação da resposta imunológica humoral e celular de camundongos machos e fêmeas. Na análise por Immunoblot avaliou-se a especificidade dos anticorpos com a cepa homóloga $\mathrm{B}: 4 \mathrm{P}: 1.19,15$. Por DOT-ELISA verificou-se a reatividade cruzada com DODAB-BF para diferentes sorogrupos (B, C, W e Y) e o mesmo não foi observado com HA. Por ELISA foram quantificados e comparados os anticorpos nos soros pool dos camundongos imunizados com DODAB-BF+OMVs e HA+OMVs para IgG, IgG1 e IgG2a. As vias de imunização utilizadas exibiram títulos de IgG. E ambos adjuvantes promoveram a produção de IgG1 e IgG2a. Por ELISpot foram analisadas as citocinas IFN- $\gamma$ e IL-4 e os resultados demonstraram uma resposta direcionada para o perfil Th1 e Th2.

Palavras-chave: Neisseria meningitidis. Camundongos neonatos. Adjuvantes. ELISpot. 


\begin{abstract}
SANTOS, F. A. O. Evaluation of difference immune response in neonatal mice using outer membrane vesicles of Neisseria meningitidis B complexed with two different adjuvants. 2017. 92 f. Masters thesis (Biotechnology) - Instituto de Ciências Biomédicas, Universidade de São Paulo, São Paulo, 2017.

Adjuvants are molecules, compounds or macromolecular complexes that increase the power and longevity of the specific immune response to antigens. Their addition in the vaccine preparation increase sustains and directs immunogenicity of antigens, effectively modulating appropriate immune responses, reducing the amount of antigen or number of immunizations required, and improving the efficacy of vaccines in infants, the elderly, or immunocompromised patients. The aim of this study was to evaluate the immunogenicity of antigenic from outer membrane vesicles (OMVs) of $N$. meningitidis B complexed with two different adjuvants: DODAB-BF and aluminium hydroxide $\left(\mathrm{Al}(\mathrm{OH})_{3}\right)$ comparing the evaluation of subcutaneous and intranasal route of immunization for the first time using the prime-boost system in outbred neonatal mice. As universal methods of antibody detection were used: Immunoblot, DOT-ELISA, ELISA and ELISpot aiming for the humoral and cellular immune response and of male and female mice. By Immunoblot analysis the specificity of antibodies with the homologous strain $N$. meningitidis B:4P:1.19,15. By DOTELISA was verified the cross-reactivity with DODAB-BF to different serogroups $(\mathrm{B}, \mathrm{C}, \mathrm{W}$ and $\mathrm{Y}$ ) that was not observed with alum. By ELISA the antibodies titers were quantified and compared in the sera of mice immunized with DODAB-BF+OMVs and alum+OMVs for IgG, IgG1 and IgG2a. The immunization routes used exhibited IgG titers, and both adjuvants promoted the production of IgG1 and IgG2a varying according to the route of immunization used. By ELISpot was analyze IFN- $\gamma$ - and IL-4 and the results showed the response directly to Th1 and Th2 profile.
\end{abstract}

Keywords: Neisseria meningitidis. Neonatal mice. Adjuvants. ELISpot. 


\section{INTRODUÇÃO}

\subsection{Neisseria meningitidis}

A bactéria Neisseria meningitidis, também conhecida como meningococo, é uma bactéria Gram negativa, aeróbia, imóvel, pertencente à família Neisseriaceae (SÁFADI; OSELKA, 2012).

A composição antigênica da cápsula polissacarídica permite a classificação do meningococo em 12 sorogrupos (A, B, C, E, H, I, K, L, W, X, Y e Z) de acordo com sua estrutura capsular, 6 deles $(\mathrm{A}, \mathrm{B}, \mathrm{C}, \mathrm{W}, \mathrm{X}, \mathrm{Y})$ causam a doença meningocócica invasiva (DMI) de ocorrência mundial, com variações sazonais e manifestações epidêmicas localizadas (HARRISON, 2015).

A distribuição dos sorogrupos varia geograficamente e temporalmente, sendo os sorogrupos $\mathrm{A}, \mathrm{B}, \mathrm{C}$ responsáveis pela maioria dos casos de DMI em todo o mundo (GABUTTI et al., 2015).

Sorogrupos B e C são prevalentes na Europa e nas Américas, sorogrupos A e C na Ásia e na África, sorogrupos W e Y prevalentes na América do Norte (GABUTTI et al., 2015) e o sorogrupo X com casos esporádicos encontrados na África subsaariana (DELRIEU et al., 2011).

As variações são reflexos das propriedades patogênicas das cepas prevalentes de $N$. meningitidis, das condições socioeconômicas, ambientais e da imunidade da população (MCGILL et al., 2016).

\subsection{Doença meningocócica invasiva}

A progressão da DMI é extremamente rápida e como medida preventiva e de controle da doença utilizam-se terapia com antibióticos e vacinas profiláticas, sendo a vacinação a melhor abordagem para a prevenção da DMI (SECRETARIA DE VIGILÂNCIA EM SAÚDE, 2014).

A incidência global de infecção pelo sorogrupo B é estimada entre 20.000 e 80.000 casos por ano (GIRARD et al., 2006).

A DMI ocorre tanto na forma endêmica como na forma epidêmica. O maior número de casos ocorre em crianças com idade inferior a 5 anos, particularmente entre 6 e 24 meses (WORLD HEALTH ORGANIZATION - WHO, 2005) e as sequelas como paralisia, surdez, 
deficiência mental, amputações e convulsões (BORROW et al., 2017) acometem de 11-19\% dos sobreviventes (MASUDA et al., 2015).

A incidência da DMI no Brasil começou a ser monitorada a partir da epidemia da década de 70, entre 1971 e 1974, atingindo cerca de 170/100.000 habitantes/ano, causada pelos sorogrupos A e C. Em 1988 houve outra epidemia situada na grande São Paulo, causada pelo sorogrupo B que se manteve até o ano de 1990 (SACCHI et al., 1992) atingindo mais de 17 milhões de habitantes em 38 municípios de São Paulo (MILAGRES et al., 1994).

$\mathrm{Na}$ década de 90 o sorogrupo B teve queda percentual acentuada de incidência, mas nos últimos 5 anos está crescendo proporcionalmente, enquanto que o sorogrupo C está diminuindo a sua incidência no mesmo período, porém esta ainda é alta no Estado de São Paulo, atingindo 55\% (figura 1) (SÃO PAULO, 2017).

Os sorogrupos W e Y também aparecem em São Paulo, entretanto a incidência é baixa, em torno de 5\% de acordo com o Centro de Vigilância Epidemiológica do Estado de São Paulo (CVE) (figura 1) (SÃO PAULO, 2017).

Figura 1 - Distribuição percentual por sorogrupos no Estado de São Paulo (SÃO PAULO, 2017).

\section{MENINGOCÓCICA: DISTRIBUIÇÃO PERCENTUAL POR SOROGRUPO, ESTADO DE SÃO PAULO, 1998 a 2016.}

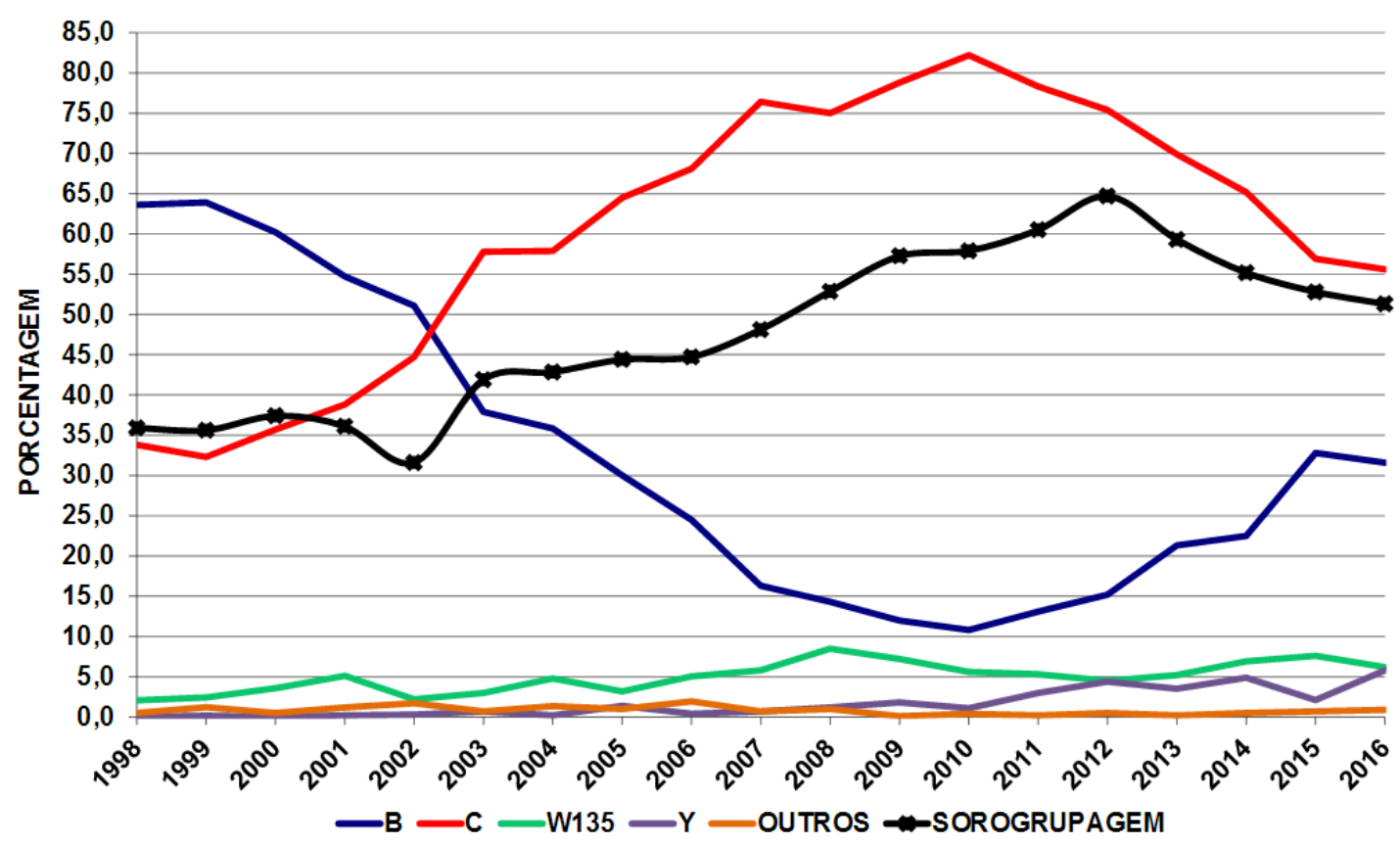

FONTE: SINAN / DDTR / CVE - ATUALIZAÇ̃̃O EM 20/04/2017.

Atualmente, a taxa de mortalidade da doença meningocócica permanece entre 10-15\% com taxas $\geq$ a $20 \%$ nos países em desenvolvimento, já a taxa de letalidade se situa entre 9- 
12\% em países desenvolvidos, sendo mais elevada em países em desenvolvimento (MASUDA et al., 2015).

\subsection{Estrutura da bactéria}

A bactéria $N$. meningitidis possui um envoltório celular consistindo de duas camadas lipídicas ao lado de uma camada semi-rígida de peptideoglicana (SADARANGANI; POLLARD, 2010).

Os principais constituintes bacterianos que contribuem para a doença meningocócica são: polissacarídeo capsular, proteínas de membrana externa (pili, porinas, moléculas de adesão Opa/Opc, e moléculas de ligação ao ferro). Outro fator de virulência importante encontrado na membrana externa são os lipooligosacarídeos (LOS), são estruturas análogas ao lipopolissacarídeos (LPS) de bactérias entéricas Gram-negativas (figura 2), contendo em sua estrutura uma porção com atividade de endotoxina, o que promove a sepse sistêmica encontrada clinicamente, além de possuir papel na adesão e colonização (QUAGLIARELLO, 2011; STEPHENS; GREENWOOD; BRANDTZAEG, 2007).

Figura 2 - Estrutura capsular de proteínas de membrana externa de Neisseria meningitidis. Adaptada (Sadarangani; Pollard, 2010).

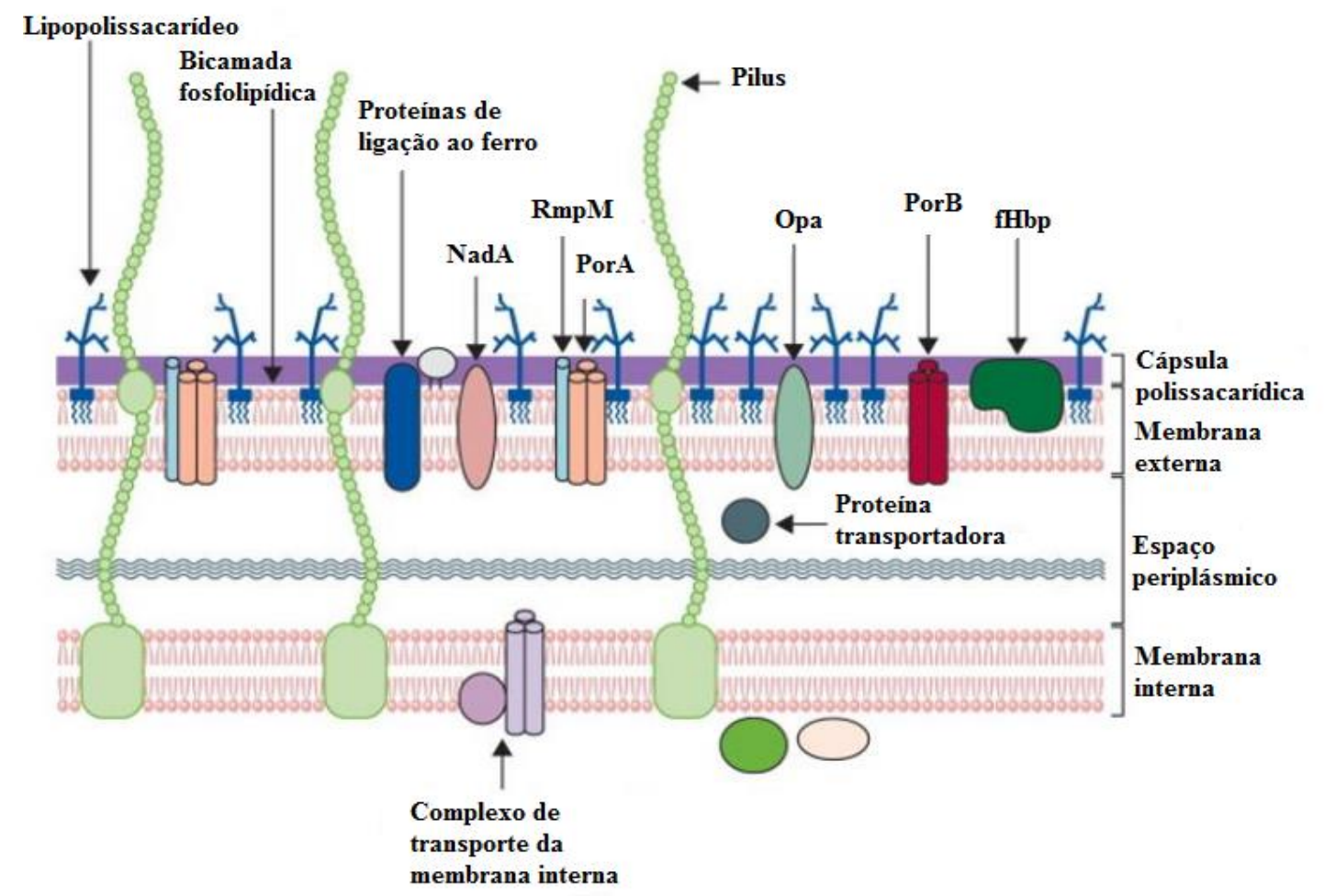


O polissacarídeo capsular desempenha um papel crucial na DMI. A cápsula confere propriedades antifagocíticas, pois permite que o meningococo escape da morte mediada pelo complemento, contribuindo para a sobrevivência desse na corrente sanguínea ou no sistema nervoso central (SNC), além de atuar como uma barreira protetora contra a dessecação durante a disseminação aérea entre diferentes hospedeiros (ROSENSTEIN et al., 2001; STEPHENS, 2009).

As proteínas de membrana externa (PMEs) apresentam 5 proteínas majoritárias classificadas de acordo com o mapeamento proteico e o peso molecular. As proteínas de classe 1 ou porina A (PorA) apresentam peso molecular de 44-47 kDa; classe 2-3 ou porina B (PorB) 33-42 kDa; classe 4 chamada também de RmpM com massa molecular de 33-34 kDa e classe 5 ou Opa/Opc, que são proteínas de opacidade com massa molecular de 25-30 kDa (POLLARD; FRASH, 2001).

Todas as cepas de meningococos expressam a proteína de classe 2 ou 3, mas nunca ambas simultaneamente, essas são agrupadas em uma única classe denominada 2-3 embora tenham sido observadas diferenças qualitativas e quantitativas em sua expressão (PIZZA; FEAVERS, 2009).

As PorA e PorB, expressas pelos meningococos, fornecem sinais para a indução de anticorpos para meningococos. A PorA é o alvo frequentemente reconhecido por anticorpos bactericidas presentes no soro e está sendo muito usada em estudos para vacinas meningocócicas, desde que se descobriu sua importância no contexto da variabilidade destas bactérias (PIZZA; FEAVERS, 2009).

As PorB são as maiores porinas presentes na membrana externa, e são capazes de se inserir nas membranas das células alvo para facilitar ligação e posterior invasão pelo meningococo (PIZZA; FEAVERS, 2009).

Além das proteínas majoritárias a $N$. meningitidis também possui proteínas reguladas pelo íon ferro do inglês denominada de iron regulated proteins (IRP) as quais são constituídas por um grupo de glicoproteínas reguladas pelo íon ferro e expressas quando $N$. meningitidis está exposta a baixa concentração ou quando o íon está ausente (PETTERSON et al., 2006).

As principais proteínas reguladas pelo ferro são TpbA e TbpB e estas atuam como receptores de transferrina, que possuem peso molecular de 93-98 kDa e 68-85 kDa respectivamente (PERKINS; RATLIFF; STOJILJKOVIC, 2004).

Outra proteína presente na superfície dos meningococos é a Neisseria adesina A (NadA), de alto peso molecular, de 170-190 kDa, que está associada à adesão e à invasão celular (POLLARD; FRASH, 2001). 


\subsection{Classificação da bactéria Neisseria meningitidis}

A bactéria $N$. meningitidis pode ser classificada de forma tradicional em sorogrupos determinados pelas diferentes estruturas capsulares de polissacarídeos; em sorotipos determinados pelas proteínas de membrana externa (PorB); em subtipos determinados pela proteína de membrana externa (PorA); e em imunotipos determinados pelo LOS. Essas classificações são realizadas utilizando anticorpos que reconhecem epítopos de superfície expostos na cápsula ou membrana externa (VAN DEUREN; BRANDTZAEG; VAN DER MEER, 2000).

Dessa forma, pode-se classificar como, por exemplo, N. meningitidis B:4:P1.19,15 onde (B) é o sorogrupo, (4) é o sorotipo, (P1.19 e 15) é o subtipo. Essa definição facilita estudar a distribuição geográfica das cepas de meningococos.

Existe outro método de classificação baseado na identificação de sequências de genes altamente conservados, o teste é denominado de multilocus sequence typing - tipagem por sequenciamento de multilocus (MLST) (GIRARD et al., 2006).

\subsection{Colonização da bactéria Neisseria meningitidis no hospedeiro}

O meningococo coloniza e infecta apenas a nasofaringe do homem, sendo transmitido de pessoa a pessoa por contato direto de secreções nasais ou orais com inalação de gotículas em aerossóis (SÁFADI; OSELKA; BEREZIN, 2012). O contato próximo com os pacientes que tem a a doença meningocócica aumenta as chances de 500 a 2000 vezes de uma pessoa adquirir a DMI (TZENG; STHEPHENS, 2000).

A capacidade de adesão às superfícies mucosas é essencial para a sobrevivência do meningococo. Os meningococos aderem à mucosa da nasofaringe, e nas microvilosidades presentes na superfície das células colunares não ciliadas, onde se multiplicam e colonizam o epitélio (ROSENSTEIN et al., 2001).

Os meningococos são capazes de se replicar intracelularmente e isso é possível, em parte, devido à sua capacidade de aquisição de ferro por meio de um sistema de transporte especializado. Este patógeno, no meio intracelular, se encontra no interior de um vacúolo e por um período de 18 a 40 horas é capaz de se translocar através de camadas epiteliais (STEPHENS, 2009).

As taxas de incidência de portadores assintomáticos aumentam em certas condições e em diferentes idades, com predominância na adolescência e em adultos jovens $(\leq 27 \%)$, mas 
muito mais baixa em idosos (por exemplo, $\leq 8 \%)$ e lactentes $(<5 \%)($ CHRISTENSEN et al., 2010).

Na grande maioria desses indivíduos, a colonização assintomática da nasofaringe por meningococos tipáveis e não tipáveis e por outras espécies de Neisseria como, por exemplo, a Neisseria lactamica, acaba funcionando como um processo imunizante, resultando em produção de anticorpos protetores (SÁFADI; OSELKA; BEREZIN, 2012).

\subsection{Cenário das vacinas}

No Brasil, por determinação do Ministério da Saúde (MS), criou-se o Programa Nacional de Imunizações (PNI) em 1973. Com o objetivo principal de coordenar as ações de imunização, o programa garantiu a continuidade de aplicação de doses do cronograma de vacinação e ampliou a área de cobertura vacinal no Brasil, alcançando médias superiores a 95\% de cobertura vacinal no caso do calendário infantil (MINISTÉRIO DA SAÚDE, 2014).

Os calendários de vacinação estão em constante revisão e ocorrem alterações frequentes em virtude de novas evidências que surgem em literatura médica do comportamento das doenças no país, assim como o impacto que elas causam na população. Desse modo, são observados critérios como magnitude, vulnerabilidade, transcendência, gravidade, relevância social e econômica (LIMA, 2015).

Em 2017 seis vacinas tiveram seu público-alvo ampliado. São elas as vacinas para: hepatite A (crianças), tetra viral (sarampo, rubéola, caxumba e varicela) (crianças), meningocócica $\mathrm{C}$ (crianças e adolescentes), dTpa (contra difteria, tétano e pertussis acelular) (gestantes), tríplice viral (sarampo, rubéola e caxumba) (adultos) e vacina contra o vírus do papiloma humano (HPV) (meninos) (MINISTÉRIO DA SAÚDE, 2017).

Em 2017, o PNI distribuiu 300 milhões de doses de vacinas e soros (MINISTÉRIO DA SAÚDE, 2017). Todas as vacinas do calendário são recomendadas pelo MS e, por isso, são oferecidas gratuitamente pelo Sistema Único de Saúde (SUS) (tabela 1). 
Tabela 1- Calendário nacional de vacinação (PORTAL DA SAÚDE, 2017).

\begin{tabular}{|c|c|}
\hline IDADE & VACINAS \\
\hline $\begin{array}{l}\text { A PARTIR DO } \\
\text { NASCIMENTO }\end{array}$ & $\begin{array}{l}\text { BCG } \\
\text { HEPATITE B }\end{array}$ \\
\hline 2 MESES & $\begin{array}{l}\text { VIP } \\
\text { PENTAVALENTE (DTP+Hib+Hepatite B) } \\
\text { ROTAVÍRUS } \\
\text { PNEUMOCÓCICA } 10 \text { VALENTE }\end{array}$ \\
\hline 3 MESES & MENINGOCÓCICA C \\
\hline 4 MESES & $\begin{array}{l}\text { VIP } \\
\text { PENTAVALENTE (DTP+Hib+Hepatite B) } \\
\text { ROTAVÍRUS } \\
\text { PNEUMOCÓCICA } 10 \text { VALENTE }\end{array}$ \\
\hline 5 MESES & MENINGOCÓCICA C \\
\hline 6 MESES & $\begin{array}{l}\text { VIP } \\
\text { PENTAVALENTE (DTP+Hib+Hepatite B) }\end{array}$ \\
\hline 9 MESES & FEBRE AMARELA \\
\hline 12 MESES & $\begin{array}{l}\text { SARAMPO-CAXUMBA-RÚBEOLA (SCR) } \\
\text { MENINGOCÓCICA C } \\
\text { PNEUMOCÓCICA } 10 \text { VALENTE }\end{array}$ \\
\hline 15 MESES & $\begin{array}{l}\text { VOPb } \\
\text { DTP } \\
\text { HEPATITE A } \\
\text { TETRAVIRAL }\end{array}$ \\
\hline 4 ANOS & $\begin{array}{l}\text { DTP } \\
\text { VOPb } \\
\text { FEBRE AMARELA }\end{array}$ \\
\hline ANUALMENTE & INFLUENZA \\
\hline $9-14$ ANOS & $\begin{array}{l}\text { HPV } 2 \text { DOSES } \\
\text { MENINGOCÓCICA C (reforço ou dose única) }\end{array}$ \\
\hline $\begin{array}{l}\text { ADOLESCENTES, } \\
\text { ADULTOS E IDOSOS }\end{array}$ & $\begin{array}{l}\text { HEPATITE B } \\
\text { FEBRE AMARELA } \\
\text { SARAMPO-CAXUMBA-RÚBEOLA (SCR) } \\
\text { DTP (reforço a cada } 10 \text { anos) } \\
\text { dTpa (para gestantes a partir da } 20^{\mathrm{a}} \text { semana) }\end{array}$ \\
\hline
\end{tabular}

Legenda: BCG - vacina contra a tuberculose. VIP - vacina contra a poliomielite (inativada). Hib (Haemophilus influenza $\mathrm{b}$ ). $\mathrm{VOPb}$ - vacina contra a poliomielite (atenuada). HPV- vírus do papiloma humano. DTP - vacina adsorvida contra difteria, tétano e pertussis - (tríplice bacteriana). dTpa - contra difteria, tétano e pertussis acelular.

Para a população pediátrica podem ser utilizadas várias doses de imunizações para induzir a proteção, como no caso da vacina contra difteria, tétano e pertussis (DTP). São administradas três vezes durante os primeiros seis meses de vida (SÃO PAULO, 2016), 
seguida de uma quarta dose depois do segundo ano de vida e uma dose reforço (booster), entre quatro e seis anos de idade (RAMSHAW; RAMSAY, 2000).

Ainda assim, alguns pacientes necessitam de doses adicionais de vacina, mesmo adultos que receberam imunização completa, como no caso da vacina DTP, para o qual um booster é recomendado a cada 10 anos ao longo da vida do indivíduo (RAMSHAW; RAMSAY, 2000).

Embora não esteja completamente claro porque algumas vacinas requerem mais imunizações do que outras, o sistema de uma dose inicial e uma dose reforço são bemsucedidas para as vacinas atenuadas (vacina oral contra a poliomielite), vacina inativada (vacina da hepatite A), vacinas de subunidade de proteína recombinante (por exemplo, vacina de hepatite B) e vacinas polissacarídicas (por exemplo, vacina Haemophilus Influenzae bHib) (DE GASPARI, 2011).

O mercado global de vacinas, mais especificamente das meningocócicas, é composto por vacinas polissacarídicas que podem ser ou não conjugadas a uma proteína carreadora e pela vacina meningocócica B recombinante (LEVI, 2014).

A Sociedade Brasileira de Pediatria (SBP) recomenda o uso da vacina conjugada quadrivalente ACWY e da vacina meningocócica B recombinante, disponíveis somente na rede privada de imunização para profilaxia da doença meningocócica (SOCIEDADE BRASILEIRA DE PEDIATRIA, 2016).

De acordo com a presidência da Sociedade Brasileira de Imunizações (SBIm), a futura iserção da vacina meningocócica B no calendário vacinal do MS, ainda gera dúvidas, porque é preciso discutir a sua prioridade e viabilidade frente às outras. E por requerer a avaliação de critérios como epidemiologia, mortalidade, custo, público-alvo, expectativa de cobertura e planejamento econômico (INSTITUTO PEDRO ARTHUR, 2016).

\subsubsection{Vacinas polissacarídicas}

As vacinas polissacarídicas, internacionalmente comercializadas, são encontradas na forma bivalente para os sorogrupos (A e C), trivalentes (A, C e W-135) ou tetravalentes (A, C, Y e W-135) (WHO, 2017).

No Brasil, as vacinas polissacarídicas estão disponíveis há mais de 40 anos e oferecem proteção para os sorogrupos A e C. As vacinas polissacarídicas apresentam limitações, pois não são imunogênicas em crianças abaixo de dois anos de idade e o tempo de proteção é limitado, não sendo capaz de induzir memória imunológica. O curto período de proteção está 
associado à possibilidade de induzir hiporresponsividade em doses subsequentes, e restringe o uso destas vacinas sendo indicadas apenas para grupos de alto risco ou para controle de surtos ou epidemias (SÁFADI et al., 2011).

\subsubsection{Vacinas polissacarídicas conjugadas}

As vacinas polissacarídicas conjugadas estão disponíveis para comercialização em vários países contra os sorogrupos A, C, W e Y (SÁFADI et al., 2006).

Mais recentemente, foi licenciada a vacina meningocócica conjugada quadrivalente ACWY, conhecida internacionalmente como Menveo ${ }^{\circledR}$ (GSK-Novartis, Itália), indicada para a imunização de crianças a partir de 2 anos de idade, adolescentes e adultos (ANVISA, 2014).

O Brasil foi o primeiro país da América Latina a incluir a vacina meningocócica conjugada C (MCC) em 2010 no programa de vacinação, preconizando a administração de duas doses, a primeira aos três meses de idade, e a segunda, aos cinco meses, com uma dose reforço aos 12 meses de idade (SÁFADI et al., 2014).

A inclusão dessa vacina no calendário de vacinação ocorreu devido à epidemiologia da doença meningocócica vivenciada no país, uma vez que aproximadamente $80 \%$ dos casos da doença eram causados pelo sorogrupo C. Entre os anos de 2011 e 2012 foi observada uma redução de $50 \%$ nas taxas de incidência da doença em crianças menores de dois anos, exatamente a mesma faixa etária que está incluída no esquema de vacinação (SÁFADI et al., 2014).

\subsubsection{Vacinas contra o sorogrupo B}

Para o sorogrupo B, as vacinas polissacarídicas foram capazes de induzir a produção de auto anticorpos e pouca imunogenicidade, pois a cápsula polissacarídica de $N$. meningitidis B, composta por ácido a2-8-Nacetil neuramínico (GASPARINI et al., 2015; LIU et al., 1971) tem semelhança química com o ácido polisiálico, presente em células humanas, particularmente encontrados no tecido cerebral fetal e bioquimicamente homóloga com a estrutura molecular de adesão do neurônio (POLLARD; FRASH, 2001).

As estratégias para o desenvolvimento de uma vacina para o sorogrupo B têm sido direcionadas para a utilização de vesículas de membrana externa, do inglês outer membrane vesicles (OMVs), também conhecida como blebs, liberadas espontaneamente durante o crescimento da $N$. meningitidis. As OMVs são estruturas de membrana de bicamadas, 
esféricas, que apresentam uma variedade de antígenos de superfície na sua forma nativa, que podem ser imunogênicas e que têm demonstrado ser importantes quando usadas em preparações vacinais (HOLST et al., 2013).

As OMVs têm sido usadas no controle de surtos contra cepas específicas desde a década de 1980, e estas apresentam eficácia clínica contra o sorogrupo B, com antígenos homólogos e anticorpos bactericidas em adultos, porém não são tão eficientes em crianças menores de 6 anos e contra cepas que expressam antígenos heterólogos (SADARANGANI; POLLARD, 2010).

A primeira vacina MenB desenvolvida altamente eficaz, foi a vacina cubana VAMENGOC-BC ${ }^{\circledR}$ (Instituto Finlay, Habana, Cuba), apresentando eficácia de 83\% e após uma campanha de vacinação em massa, a incidência doença meningocócica em Cuba caiu de um pico de 14,4/100.000 hab ao ano em 1983 para 0,8/100.000 hab ao ano em 1993-94. No Brasil, essa vacina apresentou eficácia de 70-74\% em crianças de 4-9 anos de idade, porém a vacina foi ineficaz em crianças mais jovens (SADARANGANI; POLLARD, 2010).

A vacina da Nova Zelândia foi a segunda a ser licenciada para o sorogrupo B. A partir de 1991 o país sofreu uma epidemia de doença meningocócica, com pico em 2001, sendo que esta epidemia foi causada principalmente pela cepa B:4P1.7-2,4, que foi utilizada para o desenvolvimento da vacina. Essa apresentou eficácia em 53\% dos jovens, 74-76\% dos idosos e crianças e $96 \%$ dos adultos, porém foi visto uma diminuição da imunidade em longo prazo com apenas 3-34\% das crianças com idade entre 6 semanas e 24 meses, mantendo resposta por 4-16 meses após a terceira dose, sendo necessárias múltiplas doses para uma resposta mais persistente (SADARANGANI; POLLARD, 2010).

Outros países foram acometidos com o surto da doença meningocócica, porém a vacina a partir de OMVs não foi totalmente eficaz, uma vez que a imunidade específica para o antígeno de proteína externa do tipo PorA variável entre as cepas e, portanto, a variabilidade de sequências desta proteína não permitiu uma completa prevenção (GASPARINI et al., 2014).

Assim para gerar uma cobertura suficiente durante o ano de 1990 foram incluídos elevados números de subtipos de PorA, de acordo com as cepas mais prevalentes nos países, e no caso, para a vacina experimental contra o MenB (POOLMAN et al., 1996) foram utilizadas duas estratégias com seis e nove formulações de PorA denominadas de $\operatorname{Hexamen}^{\circledR}$ e Nonamen ${ }^{\circledR}$ respectivamente, e cada combinação expressando três subtipos de PorA. Os estudos clínicos demonstraram que alguns subtipos de PorA pareciam ser imunodominantes, mas não foram desenvolvidas comercialmente. A versão combinada Nonamen ${ }^{\circledR}$ apresentou 
resultados animadores em animais, porém até o momento não foram testados em humanos (FEAVERS; MAIDEN, 2017).

Devido às limitações das vacinas de OMVs, a pesquisa por uma vacina de ampla cobertura contra o MenB utilizou a vacinologia reversa em associação com a bioinformática, caracterizando as proteínas recombinantes subcapsulares com expressão na superfície da membrana externa (GASPARINI et al., 2014).

Foram selecionados três componentes com base em sua conservação proteica entre uma ampla variedade de cepas (ou seja, os mais frequentemente encontrados na maioria das cepas) e suas respostas bactericidas são: NadA; o antígeno de ligação de Neisseria com heparina (NHBA); proteína de superfície que se liga ao fator $\mathrm{H}$ (fHbp) e OMVs da cepa NZ98/254 um componente da vacina usada no surto da Nova Zelândia, a fim de auxiliar na imunogenicidade especialmente aquelas contendo o soro subtipo classe 1 PorA P1.4 (GASPARINI et al., 2014).

O FDA aprovou duas vacinas conhecidas internacionalmente contra o Men B: Trumenba $^{\circledR}$ (Pfizer, EUA) em outubro de 2014 disponível para a faixa etária dos 10-25 anos, e composta por duas proteínas recombinantes de fHbp, uma da subfamília A e outra da B (A05 e B01, respectivamente), sendo aplicada pela via intramuscular e a Bexsero ${ }^{\circledR}$ (chamada de 4C MenB) composta por proteínas recombinates subcapsulares indicada para indíviduos a partir de 2 meses a 50 anos de idade (GSK-Novartis, Itália) em janeiro de 2015.

A vacina 4C MenB está licenciada nos países como Austrália, Canadá, Reino Unido, Estados Unidos, Uruguai e Brasil, indicada para imunização intramuscular a partir dos 2 meses de vida.

\subsection{Vias de administração de vacinas}

As vacinas aprovadas no mundo todo são administradas pela via subcutânea (S.C) ou intramuscular (I.M), o que induz resposta imune sistêmica, mas não resposta antígeno específico de mucosa (TADA et al., 2015).

A escolha da via depende da preparação antigênica utilizada. A administração pela via intranasal (I.N) possui algumas vantagens como: não é invasiva (indolor), melhor adesão do paciente e rápida absorção para o sistema circulatório via camada epitelial (TADA et al., 2015). 
A via de administração oral é indicada para substâncias facilmente absorvidas no trato gastrintestinal, a intradérmica para absorção muito lenta, a via subcutânea para soluções não irritantes de absorção lenta e ação contínua (FUNASA, 2011).

A via de administração parenteral é composta pelas vias I.M, S.C e intradérmica (I.D). A via I.M para soluções irritantes (aquosas ou oleosas) e/ou quando há necessidade de rápida absorção (FUNASA, 2011).

O uso das vias pode favorecer a imunização de tal modo que a quantidade de antígeno necessária seja reduzida (HICKLING et al., 2011).

\subsubsection{Vias de mucosa}

A mucosa é associada aos tecidos linfoides que desempenham um papel central na defesa do hospedeiro contra patógenos, que entram através do trato reprodutivo e do aero digestivo, considerada a maior via de entrada de patógenos (TADA et al., 2015).

O sistema imune das mucosas (MALT) é formado pelo tecido linfoide associado ao intestino (GALT), estruturas associadas com o bronco epitélio e trato respiratório baixo (BALT), tonsilas e nasofaringe (NALT), laringe, trato urogenital, glândulas mamárias e produto da lactação (LALT) (SINGH, 2013).

As superfícies dos tratos gastrointestinal e respiratório são recobertas por uma camada de células epiteliais que interagem com as células linfoides, chamada de epitélio folículoassociado (FAE) (NEUTRA; KRAEHENDHL, 1996). Essas estruturas são encontradas na cavidade nasal, nos brônquios e nos intestinos (OGRA, 1996). Dispersas nessa barreira, encontram-se um tipo celular - as células M, que são especializadas na captação e transporte de macromoléculas, antígenos particulados e microrganismos por meio de transcitose (SINGH, 2013).

A aderência e a captação de um microrganismo pelas células $M$ envolvem uma série de eventos que incluem o reconhecimento inicial, a íntima relação entre o antígeno e as células (que requer a expressão de genes específicos), a ativação e a sinalização intracelular. A capacidade de captação das partículas ligadas à superfície apical da membrana plasmática torna as células $\mathrm{M}$ importantes para $\mathrm{o}$ desenvolvimento de vacinas de mucosas (SRIVASTAVA et al., 2015).

Para as vacinas de mucosa, especificamente a oral, existe um número muito limitado de vacinas aprovadas para uso em humanos, tais como: vacina contra a poliomielite, vacina para rotavírus, vacina contra a cólera, vacina contra a febre tifóide e uma vacina de 
adenovírus (restrita a militares) (RHEE; LEE; KIM, 2012). Para uso nasal em forma de solução de spray está disponível a vacina para influenza vírus (AZEGAMI; YUKI; KIYONO, 2014).

\subsection{Adjuvantes}

O termo adjuvante originou-se da palavra latina Adjuvare que significa ajudar (GUY, 2007).

Os adjuvantes são moléculas, compostos ou complexos macromoleculares que aumentam a potência e a longevidade da resposta imune específica aos antígenos, causando toxicidade mínima. A sua adição na preparação vacinal aumenta, sustenta e dirige a imunogenicidade de antígenos, modulando de forma eficaz respostas imunes apropriadas, reduzindo a quantidade de antígeno ou número de imunizações necessárias e melhorando a eficácia de vacinas em recém-nascidos, idosos ou indivíduos imunocomprometidos (REED et al., 2009).

Para um adjuvante ser eficaz existem várias propriedades requeridas dos quais são: estimular uma forte resposta imune humoral e/ou celular, proporcionar boa memória imunológica, não induzir a autoimunidade e hipersensibilidade, não ser mutagênico, carcinogênico, teratogênico e pirogênico e ser estável (GUY, 2007).

Dentre os adjuvantes utilizados nos diferentes tipos de preparações vacinais destacamse os sais minerais (sais de alumínio e sais de cálcio), os derivados microbianos (Monofosforil Lipídio A - MPL), emulsões e formulações surfactantes (MF56, AS02) (emulsões óleo em água empregando o esqualeno como composto principal) (SECRETARIA DE ESTADO DA SAÚDE, 2016).

$\mathrm{Na}$ Europa, os adjuvantes derivados, microbianos, emulsões e formulações surfactantes foram licenciados desde 1997 como adjuvante para a vacina influenza. O adjuvante esqualeno tem sido utilizado para a vacina da gripe H5N1 e uma combinação de hidróxido de alumínio, MPL e um análogo de LPS, foram aprovados para utilização em vacinas contra o vírus da hepatite B (HBV) e contra o vírus do papiloma humano (HPV) (LAMBRECHT; KOLL; FIERENS, 2012).

A imunidade protetora bem-sucedida pode ser gerada como resultado de uma interação harmoniosa entre a imunidade inata e adaptativa. Os sinais imunes inatos modulam não apenas a magnitude da resposta adaptativa, mas também o repertório e a qualidade dessa resposta (GUY, 2007). 


\subsubsection{Adjuvantes de mucosa}

Há algum tempo as pesquisas tem estudado e demonstrado que as enterotoxinas do Vibrio cholerae (CT) e a toxina termo lábil (LT) da bactéria Escherichia coli, as quais estão relacionadas às toxinas da família $\mathrm{AB} 5$, possuem diversas propriedades imunes quando aplicadas como adjuvante, ou ainda quando acopladas a proteínas de diferentes antígenos, mas podem ter inesperados efeitos adversos de toxicidade e antigenecidade (FERREIRA, 2009).

Para superar as várias questões sobre toxicidade relacionadas com os adjuvantes CT e LT, tem sido desenvolvida e testada a imunização intranasal com uma subunidade recombinante da toxina B cólera, com soro albumina bovina (BSA), secretada por Bacillus previs. Recentemente, formas não tóxicas ou atenuadas de LT e CT foram produzidos por mutagênese e testado quanto à sua capacidade para servir como adjuvantes quando administrado pela mucosa nasal ou pela via oral (SRIVASTAVA et al., 2015).

Os adjuvantes CT e LT são os mais bem estudados, mas com a nova geração de vacinas os estudos de novos adjuvantes de mucosa se fizeram necessários, é exemplo o LPS, que pode ser utilizado como adjuvante para uso em vacinas de mucosas sem a porção - lípide A, derivada da bactéria Gram negativa Salmonella minnesota R595, pois assim, a reatogenicidade deixa de existir e é testada como alternativa não tóxica (SRIVASTAVA et al., 2015).

Os oligodesoxinucleotídeos sintéticos (ODN) são outros adjuvantes que são estudados em nível de mucosa, contendo a citosina-fosfato-guanina não metilada ( $\mathrm{CpG}$ modificada) (SRIVASTAVA et al., 2015).

A subunidade estrutural do flagelo bacteriano, chamada de flagelina, pode ser empregada em estratégias vacinais como carreadora ou como adjuvante, administrada por vias de mucosa ou parenteral. Também as interleucinas foram identificadas como adjuvantes na vacinação de mucosa, por exemplo, a interleucina-12 (IL-12), um estimulante imune potente responsável por desencadear a produção de interferon gama (INF- $\gamma$ ) e fator de necrose tumoral (TNF) (SRIVASTAVA et al., 2015).

Vários sistemas de administração utilizados para a imunização da mucosa foram desenvolvidos, incluindo substâncias catiônicas e nanopartículas, que podem servir como imunomoduladores, com potencial uso de segurança e eficácia como adjuvante de mucosa (TADA et al., 2015). 
$\mathrm{O}$ adjuvante brometo de dioctadecildimetilamônio (DODAB) é um lípide catiônico (CARMONA-RIBEIRO, 2006) formado por um grupo amônio quaternário, ao qual estão ligadas duas cadeias com 18 carbonos cada (figura 3) (CARMONA-RIBEIRO, 1992).

Figura 3 - Estrutura química do DODAB (CARMONA-RIBEIRO; SOBRAL; SOTO, 2008).

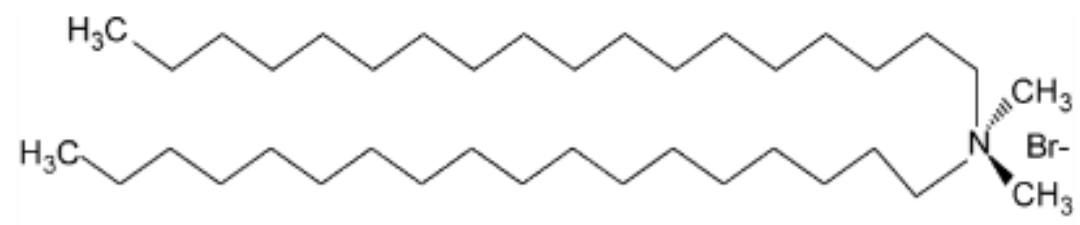

A forma molecular do DODAB-BF é cilíndrica e devido a essa estrutura molecular as moléculas de DODAB se auto complexam em soluções aquosas, em bicamada abertas ou fechadas dependendo do método de preparação. O método de vaporização clorofórmica e o de aquecimento acima da transição de fase gel para líquido-cristalina geram vesículas grandes e o método de sonicação (figura 4) gera fragmentos de bicamada (DODAB-BF) abertos e pequenos obtidos por uma baixa força iônica (CARMONA-RIBEIRO, 2003).

Figura 4 - As dispersões de fragmentos de DODAB-BF em NaCl $1 \mathrm{mM}$ obtidos por sonicação (CARMONARIBEIRO, 2010).

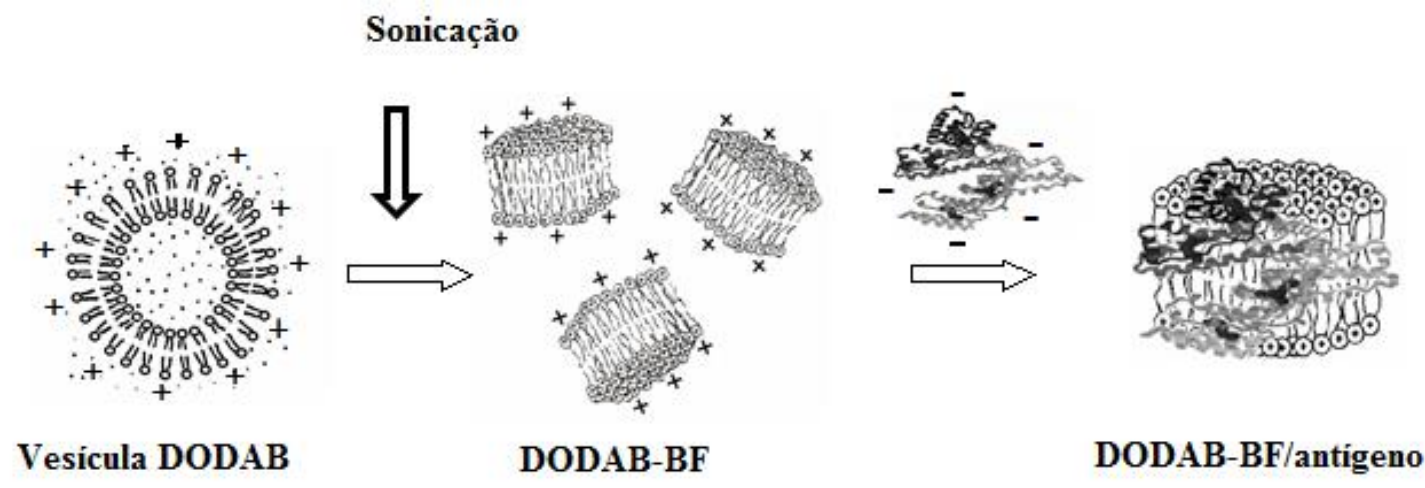

Esquema de formação dos fragmentos de bicamada (BF) de DODAB e os complexos DODAB-BF/antígeno (CARMONA-RIBEIRO, 2010). 
O DODAB-BF, também pode ser chamado de DDA-BF. Este é utilizado como um imunoadjuvante efetivo há mais de 40 anos, e tem sido estudado como modelo para vacinas pela via parenteral e de mucosa, e avaliado também como carreador de drogas antimicrobianas (LINCOPAN et al., 2003).

Com ambientes mais fluídos nas bordas, o DODAB-BF possui a vantagem adicional de permitir a adsorção por atração eletrostática de uma ampla variedade de biomoléculas ou estruturas biológicas, em sua maioria negativamente carregadas (CARMONA-RIBEIRO, 2014).

A principal vantagem de utilizar fragmentos de bicamada como imunoadjuvante é a baixa concentração de lípide necessária para atingir o efeito desejado, rápida formulação e baixo custo (CARMONA- RIBEIRO, 2014).

Em 2009, complexos entre DODAB-BF e antígenos purificados de Taenia crassiceps e uma proteína recombinante de Mycobacterium leprae foram testados in vivo, resultando na potencialização da resposta imune celular contra o antígeno testado (LINCOPAN et al., 2009).

Recentemente, estudos demonstraram uma efetiva resposta imune celular e humoral baseados na reatividade cruzada com OMVs de $N$. lactamica combinados com DDA-BF (GASPAR et al., 2013).

O adjuvante DDA foi avaliado na vacina contra tuberculose e o complexo antígeno/adjuvante demonstrou um aumento da imunogenicidade, porém os mecanismos biológicos responsáveis pelo aumento da resposta imune ainda são desconhecidos (DERRICK et al., 2015).

Em 2012, o complexo negativamente carregado com DODAB e com CpG (oligodeoxinucleotídeo) foram usados separadamente como um potente imunoadjuvante direcionando a resposta imune para um perfil Th1 (ROZENFELD et al., 2012).

Outros estudos também demonstraram os efeitos terapêuticos do peptídeo P10 combinado com DODAB em camundongos BALB/c, previamente infectados com a cepa Paracoccidioidomicose brasiliensis Pb18 e observaram reduções significativas do número de unidades formadoras de colônia (UFC), bem como reduções na formação de granulomas e fibrose (TABORDA et al., 2012).

DDA é um dos componentes do adjuvante CAF01, adjuvante em fase de estudos préclínicos em vacinas experimentais para micobactérias (AGGER et al., 2008), clamídia (OLSEN et al., 2010) e para influenza (ROSENKRANDS et al., 2011). 


\subsubsection{Hidróxido de alumínio}

Em 1926 o alumínio foi o primeiro adjuvante utilizado comercialmente para melhorar a imunogenicidade da vacina contra a difteria (MARRACK; MCKEE; MUNKS, 2009) e desde então permaneceu por mais de 60 anos como o único adjuvante licenciado (CHRISTENSEN, 2016).

Atualmente, o alumínio pode ser encontrado em várias vacinas infantis como: DTP, (DTP - Hib - Polio combinação), hepatite A e B, HPV, Hib, vacinas meningocócicas e pneumocócicas (LAMBRECHT; KOOL; FIERENS, 2012).

As pesquisas realizadas sobre os possíveis mecanismos de ação do hidróxido de alumínio (HA), de fórmula química $\mathrm{Al}(\mathrm{OH})_{3}$, têm progredido. Porém a explicação mais descrita pelos autores é a formação de depósito de antígenos nos tecidos para liberação prolongada dos antígenos particulados, facilitando a apresentação para as células apresentadoras de antígenos (APCs), no qual o antígeno é processado e apresentado para moléculas do complexo principal de histocompatibilidade de classe I e II (MHC I e MHC II), seguindo para a drenagem nos linfonodos (MARRACK; MCKEE; MUNKS, 2009).

Nos linfonodos, as células dendríticas maduram e selecionam células T específicas de antígeno, que se diferenciam em células $\mathrm{T}$ efetoras. $\mathrm{O}$ hidróxido de alumínio induz principalmente respostas de células B de longa duração e também induz a geração de células T efetoras (MARRACK et al., 2009).

Novos estudos demonstram o envolvimento e a ativação do inflamassoma NALP3 inato, podendo levar a uma resposta humoral adaptativa privilegiando a diferenciação de células T auxiliares tipo 2 - Th2 em vez de células T auxiliares tipo 1-Th1. $\mathrm{O}$ alumínio ativa as APCs por provocar a secreção de ácido úrico uma molécula gerada pelo trauma de células e tecidos (local da injeção). A citotoxicidade dos sais de alumínio causa a liberação de ácido úrico, com a formação posterior de cristais de urato monossódico, que podem ser fagocitados por macrófagos e outros leucócitos locais, levando a disrupção de lisossomas, o que resulta na liberação de catepsina B que podem ativar diretamente ou indiretamente o inflamassoma NALP3 intracelular e a caspase-1 (KOLL et al., 2008).

O alumínio é um adjuvante muito eficiente para doenças para as quais uma resposta neutralizante humoral é necessária, contudo esses são indutores pobres de respostas de células Th1. Contudo novos adjuvantes têm sido pesquisados para que se desenvolva uma resposta imune não só duradoura e forte, mas também uma imunidade mediada por células T $\mathrm{CD} 4^{+} \mathrm{e} \mathrm{T}$ $\mathrm{CD}^{+}$(GUY, 2007). 


\subsection{Resposta imune}

O desenvolvimento do sistema imunológico humano começa em estágios embrionários. Inicialmente ocorre no fígado fetal e segue para as células progenitoras hematopoiéticas na medula óssea, dando origem a linfócitos e a células polimorfonucleares (neutrófilos, eosinófilos e mastócitos) (BASHA; SUREDRAN; PICHICHERO, 2014).

O desenvolvimento e maturação de progenitores linfoides neonatais são altamente regulados por múltiplos fatores, incluindo citocinas, células estromais, fatores de transcrição e componentes da matriz extracelular (BASHA; SUREDRAN; PICHICHERO, 2014).

O sistema imunológico dos recém-nascidos torna-os altamente vulneráveis a doenças virais, bacterianas, fúngicas e parasitárias (GOTSCHLICH; ARTENSTEIN, 1969).

Crianças apresentam maior morbidade e mortalidade, aproximadamente 11 milhões morrem antes de completarem cinco anos de idade e $38 \%$ morrem durante o primeiro mês de vida, chamado de período neonatal (WHO, 2005).

O corpo humano possui vários mecanismos para evitar a invasão da mucosa e a colonização do invasor, na superfície de mucosa existem cargas de superfície e a interação hidrofóbica das células da mucosa nasal do hospedeiro, dificultando o processo de adesão da bactéria. A defesa do hospedeiro após a invasão meningocócica é determinada pela resposta humoral e celular (MEDZHITOV; JANEWAY, 2000).

Os recém-nascidos são capazes de produzir anticorpos $\operatorname{IgM}, \operatorname{IgG}$ e $\operatorname{Ig} \mathrm{A}$ após a exposição do antígeno. A aquisição completa da resposta frente ao antígeno prossegue com a diversificação do repertório de anticorpos, que não atinge padrões semelhantes aos adultos. A maturação imunológica progressiva é responsável pelo aumento gradual das respostas de anticorpos às vacinas. As respostas de anticorpos infantis são, no entanto, mais lentas e fracas e de duração mais curta (SIEGRIST; MOHR, 2016).

A presença de atividade bactericida no soro é um dos fatores que contribuem para evitar a disseminação da $N$. meningitidis no hospedeiro, protegendo-o contra a doença meningocócica (MACHADO, 2008).

Em indivíduos considerados normais, os anticorpos específicos são produzidos continuamente no organismo pela presença das diferentes cepas de meningococos e Neisseria lactamica. A presença de anticorpos da classe $\operatorname{IgG}$ e $\operatorname{IgM}$ com atividade bactericida em resposta a colonização é provavelmente o fator mais importante na prevenção da doença meningocócica. Anticorpos protetores também são produzidos por antígenos de reatividade cruzada em outras espécies de bactérias (MACHADO, 2008). 


\subsubsection{Resposta humoral}

Os mecanismos de resposta humoral incluem: lise pelo complemento, fagocitose mediada por anticorpos e citotoxicidade celular dependente de anticorpo (ABBAS et al., 2015).

Os anticorpos produzidos contra os meningococos são de diferentes classes de imunoglobulinas e portanto, têm diferenças funcionais. A IgG pode iniciar uma série de funções efetoras, como interação com componentes do sistema complemento com o C1q. Além de apresentar importante papel no desenvolvimento da resposta imune celular, como a citotoxicidade dependente de anticorpos. Os anticorpos da classe IgG em resposta a infecção são predominantemente das subclasses IgG1 e IgG3, os de subclasse IgG2 aparece em crianças mais velhas (POLLARD; FRASH, 2001).

A imunoglobulina IgA não se liga ao C1q mas bloqueia a atividade bactericida. Já o anticorpo IgM possui maior atividade bactericida do que os de classe IgG (MACHADO, 2008). Está claro que a via alternativa do complemento que não depende de anticorpo é crucial na proteção contra a doença meningocócica, mas ainda não está esclarecida, qual a importância da ativação da via alternativa do complemento na resistência à infecção causada pelo sorogrupo B (POLLARD; FRASH, 2001).

\subsubsection{Resposta celular}

Segundo Adkins (2000 e 2002), com a descoberta das populações de células Th1 e Th2, tornou-se claro que as respostas $\mathrm{T}$ celulares de células humanas de recém-nascidos e de camundongos neonatos não são deficientes, mas tendem para uma resposta do tipo Th2. Pensava-se que os recém-nascidos eram imunossuprimidos, mas muitos estudos têm demonstrado que as células imunes de neonatos são qualitativamente e quantitativamente distintas das células de adultos (ADKINS, 2014).

As funções das células $\mathrm{T}$ maduras são baseadas nos tipos de citocinas produzidas (ADKINS; CEPERO, 2000). Células Th1 secretam INF- $\gamma$, interleucina 2 (IL-2), e TNF alfa e beta e estão associadas com hipersensibilidade do tipo tardia, células Th2 secretam IL-4, IL-5, IL-6, IL-9, IL-10 e IL-13 em auxílio a respostas humorais (ADKINS; CEPERO, 2000, ADKINS, 2002).

A identificação dessas subclasses de células $\mathrm{T}$ trouxe um grande avanço para que novos estudos fossem realizados com o intuito de modular a resposta imune em neonatos. As 
novas formulações e estratégias vacinais infantis incluem a rápida indução e respostas de isotipos, indução de anticorpos de longa duração e compatibilidade com vários antígenos vacinais para administração simultânea (ADKINS; CEPERO, 2000, ADKINS, 2002). 


\section{CONCLUSÃO}

- $\quad$ OMVs da cepa B:4P:1.19,15 de $N$. meningitidis na concentração de 7,5 $\mu$ g por animal complexada com DODAB-BF, foram capazes de gerar anticorpos para a classe IgG nos soros de camundongos Swiss imunizados pela via I.N/S.C.

- $\quad$ OMVs da cepa B:4P:1.19,15 de $N$. meningitidis na concentração de $5 \mu \mathrm{g}$ por animal complexada com DODAB-BF, foram capazes de gerar anticorpos para a classe IgG nos soros de camundongos Swiss imunizados pela via S.C/I.M.

- Os soros de camundongos imunizados com DODAB-BF+OMVs pela via I.N/S.C e S.C/I.M e HA+OMVs pela via S.C/I.M reconheceram antígenos imunogênicos da cepa homóloga.

- Com relação aos índices de avidez (IA) dos anticorpos IgG total produzidos após o booster, DODAB-BF+OMVs pela via I.N/S.C apresentou avidez intermediária para os machos e para as fêmeas apresentaram alta avidez, também o DODAB-BF+OMVs mostrou efeito adjuvante igual ao HA+OMVs nos camundongos imunizados pela via S.C/I.M.

- A reatividade cruzada de soros de animais imunizados com DODAB-BF+OMVs com antígenos da cepa heteróloga de Neisseria meningitidis foi superior aos soros dos animais imunizados com HA+OMVs sugerindo, que o DODAB-BF é superior ao HA para auxiliar na geração de resposta imunológica cruzada a cepas heterólogas.

- $\quad \mathrm{Na}$ análise qualitativa para o ELISpot os camundongos machos e fêmeas imunizados pela via I.N/S.C e S.C/I.M responderam para as diferentes citocinas analisadas.

- Ao se analisar a capacidade de modulação da resposta imune do adjuvante catiônico em associação com o antígeno no período neonato, pôde verificar a sua funcionalidade em gerar anticorpos IgG em nível de mucosa e parenteral para $N$. meningitidis B. 


\section{REFERÊNCIAS*}

ABBAS AK. et al. Imunologia Celular e Molecular. 8. ed. Rio de Janeiro: Elsevier, 2015. $536 \mathrm{p}$.

ABBAS AK; MURPHY KM; SHER A. Functional diversity of helper T lymphocytes. Nature, v.383, p.787-793, 1996.

ADA GL. The immunological principles of vaccination. Lancet, v.335, p.523-526, 1990.

ADKINS B.; CEPERO E, P, R. Exclusive Th2 primary effector function in spleens but mixed Th1/Th2 function in lymph nodes of murine neonates. The Journal of Immunology, v. 164, p. 2347-2353, 2000.

ADKINS, B. A new unexpected twist in newborn immunity. Nature Medice, v.20, p.22-23, 2014.

ADKINS, B.A. Murine neonatal $\mathrm{CD}^{+}$lymph node cells are highly deficient in the development of antigen-specific Th1 function in adoptive adult hosts. The Journal of Immunology, v. 169, p.4998-5004, 2002.

AGGER, E.M. et al. Cationic liposomes formulated with synthetic mycobacterial cordfactor (CAF01): a versatile adjuvant for vaccines with different immunological requirements. PLoS One, v.3, n.9, p. 3116, 2008.

ANDRADE, A.L. et al. Impact of meningococcal $\mathrm{C}$ conjugate vaccination four years after introduction of routine childhood immunization in Brazil. Vaccine, v.11, p.2025-2033, 2017.

ANVISA Vacina meningocócica ACWY conjugada disponível em: http://www.anvisa.gov.br/datavisa/fila_bula/frmVisualizarBula.asp?pNuTransacao=10548912 014\&pIdAnexo=2325302 acessado em: 30/04/2017

*De acordo com:

ASSOCIAÇÃO BRASILEIRA DE NORMAS TÉCNICAS. NBR6023: informação e documentação: referências: elaboração. Rio de Janeiro, 2002. 
AZEGAMI, T.; YUKI, Y.; KIYONO, H. Challenges in mucosal vaccines for the control of infectious diseases. International Immunology, n.26, v.9, p. 517-528, 2014.

BASHA, S; SUREDRAN, N; PICHICHERO. Immune Responses in Neonates. Expert Review of Clinical Immunology, v.10, n.9, p. 1171-1184, 2014.

BECARIA, A; CAMPBELL, A; BONDY, S. C. Aluminum as a toxicant. Toxicology and industrial health, v. 18, n. 7, p. 309-320, 2002.

BORROW, R. et al. The Global Meningococcal Initiative: Global Epidemiology, the Impact of Vaccines on Meningococcal Disease and the Importance of Herd Protection. Journal Expert Review of Vaccines, v. 16, n. 4, p. 313-328, 2017.

BRITO, L, T. Avaliação de diferentes vias de imunização com novo adjuvante para Neisseria meningitidis em diferentes linhagens de camundongos. 2015. 114f. Dissertação (Mestrado em Biotecnologia) - Instituto de Ciências Biológicas, Universidade de São Paulo, São Paulo.

CARMONA RIBEIRO, A. M. Bilayer forming synthetic lipids: drugs or carriers? Current Medicinal Chemistry, v. 10, p. 2425-2446, 2003.

CARMONA RIBEIRO, A. M. Cationic Nanostructures for Vaccines, Immune Response Activation. Dr. Ht Duc (Ed). Available from: http://www.intechopen.com/books/immuneresponseactivation/cationic-nanostructures-for-vaccines 2014.

CARMONA RIBEIRO, A. M. Lipid bilayer fragments in disks in drug delivery. Current Medicinal Chemistry, v. 13, p. 1359-1370, 2006.

CARMONA RIBEIRO, A. M. Synthetic amphiphile vesicles. Chemical Society Reviews, v.21, p.209-214, 1992.

CARMONA RIBEIRO, A. M; CHAIMOVICH, H. Preparation and characterization of large dioctadecyldimethylammonium chloride liposomes and comparison with small sonicated vesicles. Biochimica et Biophysica Acta, v.733, p.172-179, 1983. 
CARMONA RIBEIRO, A. M; SOBRAL, C.N.C; SOTO, M.A. Characterization of DODAB/DPPC vesicles. Chemistry and Physics of Lipids, v.152, p.38-45, 2008.

CARMONA-RIBEIRO, A.M. Biomimetic nanoparticles: preparation, characterization and biomedical applications. International Journal of Nanomedicine, v.7, n.5, p. 249-259, 2010.

CHACKERIAN B, L, D, R. Conjugation of a self-antigen to papillomavirus-like particles allows for efficient induction of protective autoantibodies. Journal of Clinical Investigation, v.108: p. 415-423, 2001.

CHRISTENSEN, D.et al. Meningococcal carriage by age: a systematic review and metaanalysis. Lancet Infectious Diseases, v.10, n.12, p.853-861, 2010

CHRISTENSEN, D. Vaccine Adjuvants: Why and How. Human Vaccines \& Immunotherapeutics, v. 2, n. 10, p. 2709-2711, 2016.

COBEA/SBCAL Colégio Brasileiro de Experimentação Animal. Estatuto. Disponível em http://www.cobea.org.br/ acessado em: 12 de agosto de 2016.

COFFMANN, R. L. et al. The role of helper T cell products in mouse B cell differentiation and isotype. Immunological Reviews, n.102, p. 5-28, 1988.

CVE- Centro de Vigilância Epidemiológica. Gráficos de Doença Meningocócica - Estado de São Paulo. Disponível em: http://www.cve.saude.sp.gov.br/htm/resp/meni_dados.html acessado em: 24 de julho 2016.

CZERKINSKY, C.C. et al. A solid-phase enzyme-linked immunospot (ELISPOT) assay for enumeration of specific antibody-secreting cells. Journal Immunological Methods, v. 65, p. 109-121, 1983.

DAVIDSEN, J; ROSENKRANDS, I; CHRISTENSEN, D; et al. Characterization of cationic liposomes based on dimethyldioctadecylammonium and synthetic cord factor from $\mathrm{M}$. 
tuberculosis (trehalose 6,6'-dibehenate)-a novel adjuvant inducing both strong CMI and antibody responses. Biochimica et Biophysica Acta, v.10, p.22-31, 2005.

DE GASPARI, E.N. Application of prime-boost as a novel vaccination strategy against microbial pathogens. In. Science against microbial pathogens: communicating current research and technological advances A. Méndez - Vilas. 1 vol. Badajoz- Espanha. 2011. p. 422-227.

DE GASPARI, E.N. Comparison of dot-ELISA and standard ELISA for detection of Neisseria meningitidis outer membrane complex-specific antibodies. Brazilian Journal of Infectious Diseases, v.14, n.1, p. 35-40, 2010.

DE GASPARI, E.N; ZOLLINGER W. Expression of class 5 antigens by meningococcal strains obtained from patients in Brazil and evaluation of two new monoclonal antibodies. Brazilian Journal of Infectious Diseases, v. 5, p.143-153, 2001.

DELRIEU, I. et al. Emergence of Epidemic Neisseria meningitidis Serogroup X Meningitis in Togo and Burkina Faso. Plos one, v. 6, n.5, 2011.

DERRICK, S.C. et al. Effect of cationic liposomes on BCG trafficking and vaccine-induced immune responses following a subcutaneous immunization in mice. Vaccine, v.33, p. 126$132,2015$.

DIAKUN, K. R. et al. Immunoassay of human Neisseria meningitidis serogroup A antibody. Immunological Investigations, v. 26, p. 661-679, 1997.

FEAVERS, I, M; MAIDEN, M.C.J. Recent progress in the prevention of serogroup B meningococcal disease. Clinical Vaccine Immunology, p.1-24, 2017.

FENDLER, J. Surfactant vesicles as membrane mimetic agents-characterization and utilization. Accounts of Chemical Research, v.13, p.07-17, 1980.

FERREIRA, T. The design of new adjuvants for mucosal immunity to Neisseria meningitidis B in nasally primed neonatal mice for adult immune response. 2009. 104f. 
Dissertação (Mestrado em Biotecnologia) - Instituto de Ciências Biomédicas, Universidade de São Paulo, São Paulo.

FUNASA 2011 Manual de procedimentos para vacinação. Disponível em: http://bvsms.saude.gov.br/bvs/publicacoes/funasa/manu_proced_vac.pdf $>>$. acessado em: 09 de outubro de 2016.

GABUTTI, G. et al. Epidemiology of Neisseria meningitidis infections: case distribution by age and relevance of carriage. Journal of Preventive Medicine and Hygiene, v.56, n.3 p.116-120, 2015.

GASPAR, E.B. et al. Neisseria lactamica antigens complexed with a novel cationic adjuvant. Human Vaccines \& Immunotherapeutics, v.9, n.3, p. 572-81, 2013.

GASPARINI, R. et al. How the knowledge of interactions between Meningococcus and the human immune system has been used to prepare effective Neisseria meningitidis vaccines. Journal of Immunology Research, p. 1-26, 2015.

GASPARINI, R. et al. Neisseria meningitidis B vaccines: recent advances and possible immunization policies. Expert Review of Vaccines, v.13, n.3, p. 345-64, 2014.

GHIMIRE, T.R. The Mechanisms of Action of Vaccines Containing Aluminum Adjuvants: An In Vitro vs In Vivo Paradigm. SpringerPlus, v. 4, n. 181, p. 1-18, 2015.

GIRARD, M.P. et al. A review of vaccine research and development: meningococcal disease. Vaccine, v.24, p.4692-4700, 2006.

GIUNTINI, S. et al. Human IgG1, IgG3, and IgG3 Hinge-Truncated Mutants Show Different Protection Capabilities against Meningococci Depending on the Target Antigen and Epitope Specificity. Clinical and Vaccine Immunology, p. 698-706, 2016.

GOTSCHLICH, E.C.; ARTENSTEIN, M.S; Human immunity to the meningococcus. The role of humoral antibodies. Journal of Experimental Medicine, v.129, p. 1307-1326, 1969. 
GUY, B. The perfect mix: recent progress in adjuvant research. Nature Reviews Microbiology, v.5, p.505-517, 2007.

HARRISON, L. H. Vaccines for prevention of group B meningococcal disease. American Journal of Preventive Medicine, v.49, p.345-354, 2015.

HICKLING, J.K. et al. Intradermal delivery of vaccines: potential benefits and current challenges. Bull World Health Organ, v. 89, n. 3, p.221-226, 2011.

HOLST, J. et al. Vaccines against meningococcal serogroup B disease containing outer membrane vesicles (OMVS). Human Vaccines \& Immunotherapeutics, v. 9, p. 1241-1253, 2013.

INSTITUTO PEDRO ARTHUR Brasil sem Meningite disponível em: http://www.institutopedroarthur.org.br/noticias/361/governo-federal-licencia-uso-da-vacinameningococica-b acessado em: 09 de julho de 2016.

ISRAELI, E. et al. Adjuvants and autoimmunity. Lupus, v. 18, n. 13, p. 1217-1225, 2009.

ITO, A.Y. et al. Homologous prime-boost strategy in neonate mice using Neisseria lactamica. Vaccine, v. 27, p. 3422-3428, 2009.

JONES, T.C.S. et al. Protollin TM: A novel adjuvant for intranasal vaccines. Vaccine, v. 22, p.3691-3697, 2004.

KLEIN, S.L; FLANAGAN, K.L. Sex differences in immune responses. Nature Reviews Immunology, p.1-13, 2016.

KLEIN, S.L; MARRIOTT, I; FISH, E.N. Sex based differences in immune function and responses to vaccination. Transactions of the Royal Society of Tropical Medicine Hygiene, v.109, p. 9-15, 2015. 
KOOL, M. et al. Cutting Edge: Alum Adjuvant Stimulates Inflammatory Dendritic Cells through Activation of the NALP3 Inflammasome. The Journal of Immunology, n. 181, p. 3755-3759, 2008.

LAEMMLI, U. K. et al. Cleavage of Structural Proteins during the Assembly of the Head of Bacteriophage T4. Nature, v. 227, p. $680-685,1970$.

LAMBRECH, B.N; KOOL, M; FIERENS, K. Alum adjuvant: some of the tricks of the oldest adjuvant. Journal of Medical Microbiology, v.61, p. 927-934, 2012.

LEVI, G. Vacinas Meningocócicas. CEDIPI, 2014. Disponível em: <http://www.cedipi.com.br/blog/vacinas-meningocócicas>. acessado em: 06 de dezembro de 2016.

LIMA, E. J. F. Rotinas em imunização. Vaccine - Clínica de Vacinação, Editoração Eletrônica, p. 09, 2015.

LINCOPAN, N. et al. Novel immunoadjuvants based on cationic lipid: Preparation, characterization and activity in vivo. Vaccine, v.27, n.42, p. 5760-5771, 2009.

LINCOPAN, N. et al. In vivo activity of a novel amphotericin B formulation with synthetic cationic bilayer fragments. Journal of Antimicrobial Chemotherapy, v.52, n.3, p.412-418, 2003.

LINDBLAD, E.B. Aluminium adjuvants - in retrospect and prospect. Vaccine, v. 22, p. 3658-3668, 2004.

LIU, T.Y.et al. Studies on the meningococcal polysaccharides. II. Composition and chemical properties of the group B and group C polysaccharides. Journal of Biological Chemistry, v. 246, p.4703-4712, 1971.

MACHADO, M. S. Study of immunogenicity of Neisseria lactamica: Use of monoclonal antibodies. 2008. 102f. Dissertação (Mestrado em Biotecnologia), Instituto de Ciências Biomédicas, Universidade de São Paulo, São Paulo. 
MARRACK, P; MCKEE, A.S.; MUNKS, M.W. Towards an understanding of the adjuvant action of aluminium. Nature Reviews Immunology, v. 9, p. 287-293, 2009.

MASHBURN, W. L.; MCLEAN, R. J.; WHITELEY, M. Gram - negative outer membrane vesicles: beyond the cell surface. Geobiology, v. 6, p. 214-216, 2008.

MASUDA. et al. Mortalidade por doença meningocócica no Município de São Paulo, Brasil: características e preditores Caderno de Saúde Pública, v. 31, n. 2, 2015.

MEDZHITOV, R; JANEWAY, C. Innate immune recognition: mechanisms and pathways. Immunological Reviews, v.173, p.89-97, 2000.

MCGILL, F. et al. The UK joint specialist societies guideline on the diagnosis and management of acute meningitis and meningococcal sepsis in immunocompetent adults. Journal of Infection, v. 72, n. 4, p. 405-438, 2016.

MILAGRES, L. G. et al. Immune response of Brazilian children to a Neisseria meningitidis serogroup B outer membrane protein vaccine: comparison with efficacy. Infection and Immunity, v. 62, n. 10, p. 4419-4424, 1994.

MINISTÉRIO DA SAÚDE- Secretaria de Vigilância em Saúde. Boletim Epidemiológico, v.46, n.30, Brasília, 2015.

MINISTÉRIO DA SAÚDE- Secretaria de Vigilância em Saúde. Departamento de Vigilância Epidemiológica. Vigilância epidemiológica de eventos adversos pós-vacinação. 3. ed. Brasília, 2014.

MINISTÉRIO DA SAÚDE- Ministério da Saúde amplia vacinação em todas as faixas etárias. disponível em: http://portalarquivos.saude.gov.br/images/pdf/2017/marco/03/Novocalendario-vacinal-de-2017.pdf acessado em: 30 de abril de 2017.

MOSMANN TR, et al. Two types of murine helper T cell clone. I. Definition according to profiles of lymphokine activities and secreted proteins. Journal of Immunology, v.136, p. 2348-2357, 1986. 
NEUTRA, MR; KRAEHENBUHL J-P. $M$ cells as a pathway for antigen update and processing. Essentials of mucosal immunology. Academic Press, p. 29-36, 1996.

NICHOLLS, E. F.; MADERA, L., HANCOCOCK, R. E. W. Immunomodulators as adjuvants for vaccines and antimicrobial therapy. Ann. N.Y. Academy of Sciences, v.1213, p. 46-61, 2010.

OGRA PL. Mucosal immunoprophylaxis: An introductory Overview. Mucosal vaccines. Academic Press, p3-13, 1996.

OLSEN, A.W. et al. Protection against Chlamydia promoted by a subunit vaccine (CTH1) compared with a primary intranasal infection in a mouse genital challenge model. PLoS One, v.5, n.5, p. 10768, 2010.

PAPPAS, M.G. Dot immunobinding assay (Dot-ELISA) for a rapid clinical serodiagnosis of protozoan and metazoan diseases. Handbook of Immunoblotting of Proteins. Experimental and clinical application v. 2 p. 145-155, 1988 a.

PAPPAS, M.G. Recent applications of the DOT-ELISA in immunoparasitology. Veterinary Parasitology, n.29, p.105-129, 1988 b.

PERKINS, B; RATLIFF, G; STOJILJKOVIC, I. Iron transport systems in Neisseria meningitidis. Microbiology and Molecular Biology Reviews, v.68, n.1, p. 154-171, 2004.

PETTERSON, A. et al. Vaccine potential of the Neisseria meningitidis lactoferrin-binding proteins LbpA and LbpB. Vaccine, v.24, n.17, p.3545-3557, 2006.

PIZZA, M; FEAVERS, I.M. Meningococcal protein antigens and vaccines. Vaccine, v.27, p.42-50, 2009.

POLLARD, A. J.; LEVIN, M. Production of low-avidity antibody by infants after infection with serogroup B meningococci. Lancet, v. 356. p. 2065-2066, 2000. 
POLLARD, A.J; FRASH, C. Development of natural immunity to Neisseria meningitidis. Vaccine, v.19, n.11-12, p.1327-1346, 2001.

POLTAVCHENKO, A.G et al. Multiplex method for initial complex testing of antibodies to blood transmitted diseases agents. Journal of Virological Methods, v.236, p.231-236, 2016.

PORTAL DA SAÚDE. Calendário Nacional de Imunização disponível em: http://portalsaude.saude.gov.br/index.php/o-ministerio/principal/leia-mais-o-ministerio/197secretaria-svs/13600-calendario-nacional-de-vacinacao acessado em: 29 de abril de 2017.

POOLMAN, $\mathrm{J}$ et al. Production, characterization and control of a Neisseria meningitidis hexavalent class 1 outer membrane protein containing vesicle vaccine. Vaccine, v.14, n. 10, p.1001-1008, 1996.

QUAGLIARELLO, V. Dissemination of Neisseria meningitidis. The New England Journal of Medicine, v. 364, n. 16, p. 1573-1575, 2011.

RAMSHAW, I.A; RAMSAY, A.J. The prime-boost strategy: exciting prospects for improved vaccination. Immunology Today, v.780, p.69-83, 2000.

REED, S.G et al. New horizon in adjuvants for vaccine development. Trends in Immunology, v.30, n.1, p.23-32, 2009.

REQUEJO, H, I.Z A Meningite Meningocócica no Mundo. Dois séculos de História das Epidemias: São Paulo 2005.

RHEE, J.H; LEE, S.E; KIM, S.Y. Mucosal vaccine adjuvants update. Clinical Experimental Vaccine Research, v.1, p.50-63, 2012.

RINALDI, F.M. Imunogenicidade de antígenos de membrana externa (OMVs) de Neisseria meningitidis B associado a lípide catiônico (DDA-BF). 2014. 130f. Dissertação (Mestrado em Biotecnologia) - Instituto de Ciências Biológicas, Universidade de São Paulo, São Paulo. 
ROSENKRANDS, I.et al. Enhanced humoral and cell-mediated immune responses after immunization with trivalent influenza vaccine adjuvanted with cationic liposomes. Vaccine, v.29, p. 6283-6291, 2011.

ROSENSTEIN, N. E. et al. Meningococcal disease. N Engl J Med, v. 344, n. 18, p. 1378-88, 2001.

ROZENFELD, J.H.K. et al. Stable assemblies of cationic bilayer fragments and CpG oligonucleotide with enhanced immunoadjuvant activity in vivo. Journal of Controlled Release, v.160, p.367-373, 2012.

SACCHI C.T.et al. Emergence of a New Clone of Serogroup C Neisseria meningitidis in São Paulo, Brazil. Journal Clinical Microbiology, n. 30, v.5, p. 1282-1286, 1992.

SADARANGANI M; POLLARD AJ. Serogroup B meningococcal vaccines-an unfinished story. Lancet Infectious Diseases, v.10, n.2, p. 112-124, 2010.

SÁFADI M.A, MCINTOSH E.D. Epidemiologia e prevenção da doença meningocócica: a crítica de avaliação de vacinas políticas. Revista das Vacinas, n.10 v.12, p. 1717-1730, 2011.

SÁFADI MA, BEREZIN E, ARLANT LH. Meningococcal Disease: Epidemiology and Early Effects of Immunization Programs. Journal of Pediatric Infectious Diseases Society, n. 3 v.2, p. 91-93, 2014.

SÁFADI, M. A. P; BEREZIN, E. N.; OSELKA, G. W. Análise crítica das recomendações do uso das vacinas meningocócicas conjugadas. Journal of Pediatrics, v. 88, n. 3, p. 195-202, 2012.

SÁFADI, M.A.P; BARROS, A.P. Vacinas meningocócicas conjugadas: eficácia e novas combinações. Journal of Pediatrics, v. 82, n. 3, p. 35-44, 2006.

SÃO PAULO (ESTADO) Secretaria de Estado da Saúde Coordenadoria de Controle de Doenças Centro de Vigilância Epidemiológica CVE-2013 disponível em: 
ftp://ftp.cve.saude.sp.gov.br/doc_tec/resp/MENI_SOBRE.pdf acessado em: 03 de janeiro de 2017.

SÃO PAULO (ESTADO) Secretaria de Estado da Saúde Coordenadoria de Controle de Doenças Centro de Vigilância Epidemiológica CVE-2017 disponível em: http://www.cve.saude.sp.gov.br/htm/resp/meni_dados.html acessado em: 03de março 2017.

SECRETARIA DE ESTADO DA SAÚDE - Norma Técnica do Programa de Imunização disponível em: http://www.saude.sp.gov.br/resources/cve-centro-de-vigilanciaepidemiologica/areas-de-

vigilancia/imunizacao/doc/2016_norma_imunizacao.pdf?attach=true2016 acessado em: 24 de agosto de 2016.

SECRETARIA DE VIGILÂNCIA EM SAÚDE (SVS) - Ministério da Saúde Programa Nacional de Imunização disponível em: http://www.sbmf.org.br/pdf-eventos-2/vacinas2014/Ana_Goretti.pdf acessado em: 16 de outubro de 2015.

SHOENFELD, Y; AGMON-LEVIN, N. 'ASIA'-autoimmune/inflammatory syndrome induced by adjuvants. Journal of autoimmunity, v. 36, n. 1, p. 4-8, 2011.

SIEGRIST, C.A. Neonatal and early life vaccinology. Vaccine, v.19, p. 3391-3346, 2001.

SIEGRIST, C.A; KOVARICK. Optimization of vaccine responses in early life: The role of delivery systems and immunomodulators. Immunology and Cell Biology, v.76, p. 222-236, 1998.

SIEGRIST, C.A; MOHR, E. Vaccination in early life: standing up to the challenges. Current Opinion in Immunology, v.41, p.1-8, 2016.

SINGH, M. Novel imune potentiators and delivery techonologies for next generation vacines. Manmohan Singh, PhD, Novartis Vaccines Research Cambridge, MA, USA, Springer, p.66, 2013. 
SOCIEDADE BRASILEIRA DE PEDIATRIA calendário de vacinação 2016. www.sbp.com.br/src/uploads/2012/12/Calendrio-de-Vacinao-da-SBP-2016.pdf acessado em: 01 de agosto de 2016.

SRIVASTAVA, G. DV. et al. Mucosal vaccines: a paradigm shift in the development of mucosal adjuvants and delivery vehicles. APMIS, n.23, p.275-288, 2015.

STEPHENS, D.S. Biology and pathogenesis of the evolutionarily successful, obligate human bacterium Neisseria meningitidis. Vaccine, v.27, p. 71-77, 2009.

STEPHENS, D. S.; GREENWOOD, B.; BRANDTZAEG, P. Epidemic meningitis, meningococcaemia, and Neisseria meningitidis. The Lancet, v.369, n. 9580, p. 2196-2210, 2007.

STEVENS, T. L. et al.. Regulation of antibody isotype secretion by subsets of antigenspecific helper T cells. Nature, p.255-334, 1988.

TABORDA, C.P. et al. The role of adjuvants in therapeutic protection against Paracoccidioidomycosis after immunization with the P10 peptide. Frontiers Microbiology, v. 3 , p. $154,2012$.

TADA, R. et al. Intranasal immunization with DOTAP cationic liposomes combined with DC-cholesterol induces potent antigen-specific mucosal and systemic immune responses in mice. Plos One, v.6, p. 1-21, 2015.

TANGUAY, S; KILLION, J.J. Direct comparison of ELISPOT and ELISA-based assays for detection of individual cytokine-secreting cells. Lymphokine cytokine research, v.13, n.4, p.259-263, 1994.

TZENG, Y. L.; STEPHENS, D. S. Epidemiology and pathogenesis of Neisseria meningitidis. Microbes Infection, v. 2, n. 6, p. 687-700, 2000. 
VAN DEUREN,M; BRANDTZAEG, P; VAN DER MEER, J.W. Update on meningococcal disease with emphasis on pathogenesis and clinical management. Clinical Microbiology Reviews,v.13, n.1, p.144-166, 2000.

VERMONT, C. L. et al. Antibody avidity and immunoglobulin G isotype distribution following immunization with a monovalent meningococcal $\mathrm{B}$ outer membrane vesicle vaccine. Infection and Immunity, v. 70, p. 584-590, 2002.

VIDARSSON, G; DEKKERS, G; RISPENS, T. IgG Subclasses and Allotypes: From Structure to Effector Functions. Frontiers in Immunology, v.5, p.1-17, 2014.

WEDEGE, E. et al. Serotyping and subtyping of Neisseria meningitidis isolates by coagglutination, dot-blotting and ELISA. Journal of Medical Microbiology, v. 31, p. 195-201, 1990.

WEGMANN, F. et al. Polyethyleneimine is a potente mucosal adjuvante for viral glycoprotein antigens. Nature Biotechnology, v.30, p.883-888, 2012.

WHO- World Health Organization. disponível em: http://www.who.int/ith/vaccines/meningococcal/en/ acessado em: 24 de março de 2017.

WHO- World Health Organization. Saúde dos recém-nascidos: chave para a sobrevivência da criança. disponível em: http://www.who.int/maternal_child_adolescent/documents/pdfs/lancet_neonatal_survival_seri es_pr.pdf 2005 acessado em: 14 de março de 2017. 